\title{
Brain nutrition-orthomolecular aspects
}

\author{
Roni L. Moya ${ }^{1,2 *}$ \\ ${ }^{1}$ Escola Superior de Saúde do Vale do Ave-CESPU, Portugal \\ ${ }^{2}$ Stellar Biomolecular Research-Frankfurt am Main, Germany
}

\begin{abstract}
The contemporary advances in neuroscience and anti-aging medicine show that the brain and nervous system can adapt to chronic stress, inflammation and damage mechanisms by increasing its neurogenic and neuroplasticity potential. Neuroplasticity is the key point response of adaptation and repairing of functional neurons throughout life, giving the opportunity, either by DNA restoration, releasing of neurotrophins, antioxidant defences, mitochondrial, inflammatory and apoptotic regulation to fight against the neurological aging typical decline. The perfect neuroplastic development will depend on a multi imperative factors and concepts, such as epigenetics, dietary anti-inflammatory/antioxidant nutrition, caloric restriction, mindfulness meditation ability, novelties experiences, sleep cycle quality, exercise, physiological and psychological stress coping, hormonal balance and cellular or tissues regenerative molecules. The orthomolecular medicine establishes the use of the correct molecules to keep the perfect physiological and biochemical function of the body and by using this wide-range Linus Pauling definition this mini-review aims to address the main issues related to the mechanisms of cognitive and neuroplasticity development and offers the best perspectives to approach neurodegeneration and aging related neurological diseases.
\end{abstract}

\begin{abstract}
Abbreviations: AGEs: Advanced glycosylated end products; AA: Arachidonic acid; BDNF: Brain-derived neurotrophic factor; BNP: Brain natriuretic peptide; COX-2: Cyclooxygenase type 2; DHA: Docosahexaenoic acid; DHEA: Dehydroepiandrosterone; EPA: Eicosapentaenoic acid; FPSCXT: Precursor stem cell xenotransplants; FGF-2: Fibroblast growth factor 2; GABA gabaminergic acid; GDNF: Glial cell-derived neurotrophic factor; IGF-1: insulin-like grow factor 1; Nrf2: Nuclear erythoid factor 2;iNOS: Nitric oxide synthase; IL1 $\beta$ : Interleukin $1 \beta$; IL-6: Interleukin 6; IL-8: Interleukin 8; MSCs: Mesenchymal stromal cells; NF- $\kappa$ : Nuclear factor kappa $\beta$; NGF: Nerve growth factor; NMDA: N-methyl-n-aspartate; PG2: Prostaglandin-2; PUFAs: Polyunsaturated fatty acids; ROS: Reactive oxygen species; SCF1: Chemokine stromal cell-derived factor-1; SIRT1: Sirtuin 1; TNF- $\alpha$ tumor necrosis factor; TGF- $\beta$ : Transforming growth factor- $\beta$; VEGF: Vascular endothelial growth factor
\end{abstract}

\section{Introduction}

One of the greatest burdens of the globally aging population is the decline of cognitive faculties. Experts alert about the number of people with dementia, which will duplicate by 2030 and triplicate by 2050 [1]. As the knowledge about dementia and aging develops, it's becoming clearer that unlike most diseases of the young, aging conditions involve multiple factors. When damage exceeds the brain's ability to repair itself, a trigger of cellular and metabolic cascades begin in order to fulfill the mechanisms of neurodegenerative pathways. At 40 years of age, the human being might achieve the evolutionary purpose of perpetuating the species and as consequence, from a biologic perspective; the daily repair of brain's cells can no longer keep up with the daily damage. Thus, the neurological function starts to decline continuously [2]. It was previously understood that the number of brain's cells would never change throughout life and the dying neurons and synapses could never more be restored. In the 1990's, William Shankle and his colleagues discovered that the human brain can generate new nerve cells and neurons after birth and subsequent discoveries by Gage, Gould and others pointed that the "plastic" human and primate brain continue to make neurons in the cerebral cortex during lifespan $[3,4]$. The established "neurogenic" (originated active proliferative neural cells and growth factors) regions are the dentate gyrus of the hippocampus, the subventricular zone (the source of neocortical neurons in development), and the olfactory lobe $[5,6]$. In summary, the number of new neurons produced, matches the number of neurons lost in each area, but as soon as the dying cells are being faster removing from the brain's regions, the physiologic balance will be lost and the cognitive and neurologic function will decline. As a relative new concept in neurosciences, the neuronal plasticity refers to changes at the neuronal level, known to be stimulated by experience, e.g., neurogenesis, synaptogenesis, dendritic arborization, and network re-organization [5]. Cognitive plasticity refers to changed patterns of cognitive behavior, e.g., greater susceptibility to distractors, and dependence on executive control, both increased in aging. Manifestations of cognitive plasticity depend upon neural plasticity mechanisms and in the absence of disease; factors that enhance this interactive process can promote both cognitive integrity (preserved cognitive ability) and brain integrity (preserved brain structure) in healthy old age [5]. During lifespan, the brain may adapt to stress by triggering several regenerative mechanisms, such as DNA repair, neurotrophic releasing, enzymatic antioxidant defense and synaptic reconnections [7-9]. Since the discovery of the adult neurogenesis, much research effort has been devoted to study its mechanisms and implications in healthy and pathological conditions. Some elucidated neurogenic mechanisms involve neurotransmitters (such as dopamine,

Correspondence to: Roni L. Moya, BMD, MSc, PhD, Escola Superior de Saúde do Vale do Ave-CESPU, Portugal, Stellar Biomolecular ResearchFrankfurt am Main, Germany, E-mail: info@ronimoya.com

Key words: antioxidants, aging, brain, diet, exercises, inflammation, neurons, neuroplasticity, orthomolecular, oxidative stress, polyphenols, regeneration, xenotransplantation

Received: May 03, 2017; Accepted: June 05, 2017; Published: June 07, 2017 
glutamate, and serotonin), hormones (such as thyroid hormones and melatonin), signaling pathways (Notch, Wnt/ $\beta$-catenin, NAMPTNAD, etc.), transcription factors (Sox-2, the orphan nuclear receptor TLX, Nrf2, etc.), growth factors (brain-derived neurotrophic factor BDNF, insulin-like grow factor-1, fibroblast growth factor 2, etc.) and epigenetic factors, which is the study of the influence of a particular gene expression and function into a specific phenotype $[10,11]$. The orthomolecular medicine establishes the use of the correct molecules to keep the perfect physiological and biochemical function of the body. Orthomolecular medicine is the restoration and maintenance of health through the administration of adequate amounts of substances that are normally present in the body. Nobel Prize winner Linus Pauling, one of the leading molecular chemists of the century, established this definition of orthomolecular medicine in 1968. The aging process is typically accelerated as a result of free radical exposure, frequent or chronic inflammation, and toxic exposures (such as to heavy metals or industrial and agricultural hydrocarbons). Reversing this process or slowing it down is one goal of orthomolecular therapy, along with treatment of health problems [12]. Within this orthomolecular concept, different factors will assist the ability to adapt cognitively and age successfully with the best neuroplastic potential, such as the natural retention of normal mechanisms of neuronal plasticity, the stimulation by novelty (new experiences, including learning), the sustained neural integrity supported by diet, hormones, own cell's neurotrophic nutrients, exercise and other factors, including genetic polymorphisms, stress, immunity and environmental influences.

\section{Neurodegeneration and inflammation}

Inflammation isbehind the highest potentialmechanism-underlying decline in brain health. The pathways linking pro-inflammatory levels in the circulating blood with brain health have been examined in detail in many excellent reviews and in summary a number of peripheral blood markers of inflammation have been related in studies of brain aging with key markers including transcription nuclear factor kappa $\beta$ [NF- $\kappa \beta$ ], interleukin [IL]-6, IL-1 $\beta$, tumor necrosis factor [TNF]- $\alpha$, IL-8 [13]. In contrast to IL-1 $\beta$ and TNF- $\alpha$, which decay rapidly, levels of IL-6 and C-reactive protein can be reliably detected in peripheral circulation and are widely assumed to reflect systemic levels of inflammation [14]. For instance, microglia cells are associated with inflammation and are present in plaques of Alzheimer disease with several inflammatory markers activated. The pro-inflammatory cytokines increase expression of $\beta$-amyloid, which leads to more inflammation [15]. Under chronic inflammatory stimuli, the microglia cells will release a continuous substantial production of pro-inflammatory factors, which will be responsible for the enhancement of neuronal toxicity and promotion of brain abnormalities [14]. Inflammation also leads to the increasing of oxidative stress and vice-versus. The constant releasing of free radicals, either due to increasing of psychic stress, disruption of the hypothalamic-adrenal axis and higher cortisol promotion; oxidative stress trigger markers like hyper-homocysteine, environmental toxins, hyperglycemic advanced glycosylated end products [AGEs], alcohol, salt, saturated fat, tobacco, etc.; or to genetic predisposition, such as the carrying of the APOE4 allele as opposed to the 2 or 3, which enhance the Alzheimer's possibility by decreasing the natural antioxidant capacity in the brain; also plays an important role in neurodegeneration. Once the radical reactive oxygen and nitrogen species are high, several called "death genes" will be switched on, for example, nitric oxide synthase [iNOS] and cyclooxygenase type 2 [COX-2] enzymes, which will convert arachidonic acid [AA] in prostaglandins and then the redundant production of cytokines. Connecting the idea of microglial activation, neurotoxicity and inflammation, there is indeed a previous mitochondrial dysfunction and reactive oxygen species [ROS] formation. The normal neuron's mitochondria produce an adequate ATP that keeps the so-called N-methyl-n-aspartate [NMDA] receptor magnesium block. However, if there are deficiencies of ATP production, the electrochemical gradient is altered and the magnesium block in the NMDA receptor is relaxed, leading to an influx of calcium, damaging the mitochondria, which further exacerbates the energy production capabilities, trigger the apoptosis and causes again the inflammatory and ROS feed forward cycle [16].

\section{Diet, inflammation, caloric restriction and neuroplas- ticity}

Diet can be one of the most stimulating stress and inflammatory factor in the brain. Mechanistic studies have shown how various dietary components can modulate key pathways to inflammation, including sympathetic activity, oxidative stress, transcription factor nuclear kappa B [NF- $\kappa \beta$ ] activation and pro inflammatory cytokines production [17]. Behavior studies have demonstrated that stressful events and depression can also influence inflammation through the same process [17]. Diets promoting inflammation can be shortly summarized in higher consumption of refined starches, sugar, saturated and trans-fat, with lower ingestion of omega- 3 fatty acids and natural antioxidants [vegetables, fruits, whole grains, etc.]. To clarify, whole grains are healthier than refined grains due to the process of refining carbohydrates, which results in the elimination of much of the fiber, vitamins, minerals, phytonutrients and essential fatty acids [18]. Moreover, refined starches and sugars can rapidly alter blood glucose, leading to insulin resistance and hyperglycemia, increasing drastically the oxidative stress and the activation of the inflammatory cascade [17]. In fact, some evidence suggests that the addition of antioxidants or vegetables may limit or even reverse proinflammatory responses to meals high in saturated fat [19]. Several lines of research have implicated inflammation in the pathophysiology of depression. Psychological stress and depression motivates less healthy food choices, being associated with less fruit and vegetables consumption as well as greater snacks, sweets and fast foods intake. From this perspective, inflammationenhancing diets could fuel depressive symptoms-and could thus boost inflammation [20]. For example, disturbed sleep, a common response to negative emotions and emotional stress responses, promotes IL-6 production [21]. A longitudinal data from Health Professionals Study showed that men decreased their vegetable intake following divorce and increased consumption after remarriage [17].

Caloric restriction is another very interesting issue to be addressed in neuroplasticity. Calorie restriction with adequate nutrients has been associated with health benefits through increased longevity in organisms from yeast to flies, worms, and mammals. Research suggests that hara hachi bu, or "eat until you are $80 \%$ full," has been an important factor in exceptional longevity with increased health span for one human population [22]. Reducing calories by $30 \%$ was associated with an average of $20 \%$ improvement in verbal memory after 3 months [23]. There is as well an influence of the caloric restriction in the sleep cycle in order to regulate the melatonin and cortisol balance and adjusting the circadian rhythm, which will benefit longevity [24]. Reducing caloric intake seems to improve synaptic resilience to damage and modify the number, architecture, and performance of synapses [25]. On the contrary, high caloric intake is perceived as a risk factor for Alzheimer Disease $[\mathrm{AD}]$, in which saturated fat consumption has been observed to promote $\mathrm{AD}$ type $\beta$-amyloidosis in mice, whereas this is prevented by dietary restriction based on reduced carbohydrates [26]. Neither calorie restriction nor intermittent fasting should be taken lightly. Each 
requires healthy nutrition. Independently of the restriction of calories, the best choice of diets for longevity and neuroplasticity should be either the Okinawan Diet [22] or the Mediterranean Diet [27]. They have a very important point in common, being both rich in vegetables, fruits, anti-inflammatory polyphenols, antioxidants, unsaturated fatty acids, fish and low glycemic load food. [28]. Hence, in accord with several perspectives, the total intake of food and fluid, frequency of intake and content consumed, will influence all factor into the molecular events of energy metabolism and neuroplasticity [29].

\section{Dietary factors and neuroplasticity}

BDNF is a neurotrophin considered generally beneficial for maintaining neuronal function and for promoting recovery after neurologic insult. BDNF is profuse in the hippocampus and cerebral cortex, and is found in lesser amounts in the hypothalamus and spinal cord. In addition to regulating the survival, growth, and differentiation of neurons during development, BDNF stimulates synaptic and cognitive plasticity in the adult brain [30]. Dietary supplementation with nutrients such as omega-3 fatty acids and curcumin have been shown to elevate levels of brain-derived neurotrophic factor [BDNF] and can exert their influences on repair and maintenance of neural circuits, important for learning, memory and locomotion [31].

\section{Omega-3 fatty acids}

Also crucial to optimal central nervous system structure and function are the essential omega-3 fatty acids eicosapentaenoic acid [EPA] and docosahexaenoic acid [DHA]; which humans cannot create [32]. Arachidonic acid [AA] derived [omega- 6 or $n-6$ ] eicosanoids [primarily from refined vegetable oils such as corn, sunflower, and safflower] increase the production of proinflammatory cytokines IL1 , TNF- $\alpha$, and IL-6, operating as precursors of the proinflammatory eicosanoids of the prostaglandin [PG]2-series. In contrast, the omega-3 [ $n$-3] polyunsaturated fatty acids [PUFAs], found in great abundance in certain fish [particularly wild-caught salmon], fish oil, walnuts, wheat germ, and some dietary supplements such as flax seed products can curb the production of AA-derived eicosanoids [33]. Omega-3 fatty acids have provided some of the strongest evidence for the profound effects that dietary factors can have on the brain. The omega-3 derived essential fatty acid docosahexaenoic acid DHA is a key component of neuronal membranes at sites of signal transduction at the synapse, which suggests that its action is vital for brain function [34]. DHA can contribute to support synaptic membrane fluidity, to elevate levels of BDNF, to reduce oxidative stress, and to regulate cell signaling [35]. In the Framingham Heart Study, people whose DHA level was in the top quartile had a highly significant $47 \%$ lower risk for developing dementia [36]. A random controlled trial that supplemented with fish oil found "increased red blood cell omega-3 content, working memory performance, and BOLD signal in the posterior cingulate cortex during greater working memory load in older adults with subjective memory impairment", suggesting that supplementing with omega-3 fish oil could enhance brain cell response to challenges in working memory [37].

\section{Dietary polyphenols}

Polyphenols are multiple phenolic structures found in plants with a powerful antioxidant and anti-inflammatory properties. The most important group of polyphenols described for their advantageous benefits in promoting neuronal repairing and neuroplasticity are the flavonoids and curcuminoids. Flavonoids are found in many fruits and vegetables or their subproducts, such as berries [e.g., blueberries, strawberries], tea, and red wine [38]. For instance, the polyphenol resveratrol, a nonflavonoid polyphenol with 2 isomeric forms: the biologically inactive cis-resveratrol, and the biologically active transresveratrol [trans-3,4, 5-trihydroxystilbene], increases longevity while preserving memory and hippocampal microstructure. This polyphenol occurs naturally in grapes, purple grape juice and some berries such as blueberries and cranberries [39]. Resveratrol may exert protective effects through scavenge ROS produced by NADPH oxidase, activate SIRT1 [Sirtuin 1], which leads to restoration of mitochondrial function and biogenesis, and stimulation of biosynthesis of "vitagenes", and inhibit microglial activation [40]. Curcumin comes from the rhizome, or root, of the turmeric plant and is used frequently in Indian dishes [producing the familiar yellow color of curry]. Curcumin is the principal curcuminoid found in the Indian plant turmeric, which has gotten a reputation for its strong medicinal capacity. Curcumin has been extensively studied and shown to benefit the brain by providing protection, through multiple mechanisms, against neurologic disorders. Curcumin has the capacity to enhance neurogenesis and increase the number of neural stem cells in the hippocampus of adult mice [41]. As an antioxidant, anti-inflammatory, and anti-amyloidal agent, curcumin can improve cognitive function in patients with Alzheimer disease [AD] [31]. Healthy humans aged 60-85 appreciated improvements in cognition and mood [42]. Other invaluable polyphenols that get much wider dietary acceptance are the flavonoids found in cocoa, which are noted for powerful anti-inflammatory as well as antioxidant effects. A review of the neuroprotective effects of the flavonoids in cocoa suggested that they "provoke angiogenesis, neurogenesis and changes in neuron morphology, mainly in regions involved in learning and memory" [43]. Another review similarly found that cocoa flavonoids are neuroprotective and can enhance mood and cognitive function [44]. Humans aged 50-69 years who consumed $900 \mathrm{mg}$ of cocoa flavanols daily for 3 months enjoyed improved dentate gyrus performance on cognitive testing as well as on fMRI [45]. Green tea is rich in flavonoids, particularly catechins such as epigallocatechin-gallate, epigallocatechin, epicatechin, and epicatechin-3-gallate. Green tea is commonly consumed in China and throughout Asia, and its consumption is perceived as beneficial for the general health of the organism [31]. Daily doses of the compound GTcatechin, an antioxidant found in green tea, has been shown to help prevent memory loss and DNA oxidative damage [46].

\section{Other antioxidant nutrients}

Different nutrients have positive effects on neural and cognitive function due their antioxidant and mitochondrial protective action [31]. The folate or folic acid, which is found in spinach, meat liver, beans, broccoli, etc., during three years of supplementation, can reduce or prevent the brain-aging decline and dementia [47,48]. Alpha lipoic acid is an important mitochondrial energy maintenance coenzyme; present in kidney, liver, heart, broccoli, spinach and potatoes [49]. Alpha lipoic acid can reduce the cognitive decline in Alzheimer's disease [50]. Vitamin E repairs the cellular synaptic membrane against oxidation and affects neuroplasticity [51]. Coenzyme Q10 is a very potent antioxidant with significance to enhance the mitochondrial activity. CoQ10 may have potential to effect the course of neurological diseases in which mitochondrial function is impaired and oxidative stress and damage are present. In a randomized double blind study from Shults, 80 people with Parkinson's disease who were not receiving other treatment were given 1200 milligrams of CoQ10 a day. After 16 months, $47 \%$ reduction in the rate of decline in the group receiving CoQ10 was observed [52]. Vitamin D is a CNS active neurosteroid with the capability to cross the cell membranes and link to their vitamin D 
nuclear receptors, switching on more than 1000 genes and modulating a gigantic network of neurological mechanisms such as cellular proliferation, differentiation and calcium homeostasis [53]. Further antioxidants may be also part of a functional neuroplastic diet, such as choline, combination of vitamins [C, E, carotene], calcium, selenium, zinc and creatine, which delay brain decline, promote longevity and cellular energetic nerve tissues storage and repair etc. [54-58].

\section{Exercise}

Associated with the proper functional diet, physical activity can boost neuronal function and plasticity by enhancing synaptic plasticity and reducing inflammation and oxidative stress. Different high levels of physical fitness have the ability to affect energetic metabolism and BDNF neuroplastic stimuli, function as an adjuvant to the anti-aging dietary choices. Exercise strengthens the hippocampal volume and its integrity and counter-balancing the hippocampal atrophy. It's as well a benefic competitor against the high saturated fat and sucrose proinflammatory behavior on the brain [59-61]. Aerobic exercise increases neurogenesis, survival and maturation of neurons in humans $[62,63]$. A random controlled trials review in elders suggested that physical exercise my increase grey brain matter and prevent cognitive behavioural losses associated with brain atrophy [64]. In summary, exercise has the capacity to enhance learning and memory under various aspects, restore neurofunction and even facilitate brain recovery after injuries. [65]. In conclusion, regular exercise is an important strategy to attenuate the neurodegenerative aging process and protect against mental disorders [66].

\section{New experiences, meditation and sleep}

Newness is very essential to enhance attention and cognition [67]. The Mayo Clinic Study of Aging, designed with 1,995 people without dementia, among 70-89 years old, of whom 277 had mild cognitive impairment [MCI]; shows the connection between career and academic achievements with a degree of cognition impairment delaying by 8.7 years. Independently of lifetime, deal with new challenges and obstacles can serve as a powerful intellectual tool to reach significant results to live healthier and longer. [68]. About artistic skills and neuroplasticity, music is one of the most multisensory form of promote neuroplasticity. Once the individual is able to read a music sheet, he or she has to translate or interpret the visual code of the music notes to a mathematic value that, consequently, will be transformed into rhythms or sounds, subjective harmony and motor skills on the chosen musical instrument. Music is capable of activate at the same time millions of neural networks and stimulate the most diverse brain areas. It's clear that this audio-visual and abstract integration will develop neurogenesis [69,70]. In 2013, people between 60 to 84 years old have been studied during 4 months of piano lessons and the results showed an improvement of attention, mood, cognitive skills, motor function, visual memory and executive functioning [71-73] suggested that 60-75 minutes of music training for a period of 5 to 6 weeks is good enough to help elderly to reverse age-related decline. Speed Training Computer Analysis report a 5 years long maintenance with immediate cognitive and motor gains, regardless of age, education, mental status and health condition when someone receives a routine of music training [74]. Concerning meditation and neuroplasticity, long-term meditation practitioners, ages from 24-77 years old, demonstrated less brain gray matter atrophy with aging [75]. This and other continuously publishing scientific articles reinforce the hypothesis that mindfulness meditation is brain-protective and will benefit the white and gray brain plasticity, as much as will act on the anti-inflammatory and antioxidant cellular and molecular defence pathways, having the similar responsive mechanisms of the targeted prescription pharmaceuticals and function as a valuable brain anti-aging tool [76,77]. At last but not least, sleep well and respecting the circadian "chronorhythm" influences the energetic metabolism, restoring brain capacity during the periods of rest. Once awake, the neural consumption can be very high and the excess production of cortisol and adrenergic hormones during a long period of time can "burn" energy enough to reduce gray brain matter [78]. Research done in 2.822 from 67 years and older associates the sleep disruptions with inflammatory increasing, reduction of BDNF and cognitive decline $[79,80]$. A balanced restoring sleep is essential for the neuronal detoxification processes and distribution of glucose, lipids, amino acids, growth factors and neuromodulators throughout the nervous system, as well as to reduce the inflammatory and stress cascade [81].

\section{Hormones}

It's a fact that cognitive decline is associated with aging. Within this process, there is a progressive reduction of several key neuroprotective hormones, with an emphatic decrease after 35 years old. Melatonin, a neurohormone produced in the pineal gland, will decline with aging in the same way as the potential of long term neuronal selfrenewal does, i.e., the reduction of melatonin will affect neuronal repair [82]. Melatonin is involved in an enormous biochemical and molecular interlocking system acting on the regulation of seasonal and circadian rhythms, antioxidant mechanism, immune response, etc. [83]. Melatonin is a powerful free radical scavenger antioxidant that ameliorates the mitochondrial energetic physiology in order to be neuroprotective, including against the beta-amyloid peptide [A $\beta]$ damaging [84-87]. Melatonin prescription increases the hippocampal, neuronal and dendritic precursor cell development, differentiation, maturation and survival $[88,89]$. DHEA [dehydroepiandrosterone] is a cholesterol derived steroid secreted by the adrenal glands, gonads and CNS cells with its decline along aging associated with increasing of cognitive deficit, depression, hippocampal reduction and dementia, including Alzheimer's Disease [90-92]. DHEA increases the expression of the glial cell-derived neurotrophic factor [GDNF] invigorating the dendritic arborisation and neurogenesis [93,94]. Leptin, an adipose-like adipokine, known by its several roles in food intake and energetic expenditure metabolism, can also regulate apoptosis, protect against oxidative damage and stimulate neuroplasticity, axon growth, synaptogenesis and proliferation of hippocampal and dendritic stem cells [95-97]. About other hormones, it's a major recognition the widerange role of the steroids hormones on the nervous system, which contains specific receptors from the most important peripheral organs like ovaries, testes and adrenal cortex [98]. Testosterone takes part in the nervous system development and exerts neurotrophic actions on the neuronal differentiation and increasing in neurite outgrowth after activation of androgen pathways in the cultured neural cells [99-101]. Testosterone supplementation during 6 weeks improves both spatial and verbal memory in healthy older men aged 50-80 years [102]. There are several potential mechanisms of testosterone protection against neurodegeneration connected with Alzheimer Disease [AD]. One of them is prevention of tau protein hyperphosphorylation [103]. Testosterone increases expression of nerve growth factor and mediates promotion of neurite growth and interneural communication through branching and arborization [104]. Estrogens have also long been known to influence nervous system development and function [105107]. It has become clear that estrogens can exert effects in multiple regions of the brain, including the cerebral cortex and hippocampus 
[108]. Estrogen induces rapid changes enhancements in memory consolidation and increases dendritic spine density [109]. Progesterone treatment increases the mRNA BDNF protein levels and protects against spinal cord injury by decreasing the chromatolysis cell number, which is a typical characteristic of motoneuron degeneration $[98,110]$. Progesterone acts on the $\mathrm{GABA}_{\mathrm{A}}$ [gabaminergic acid] receptors having an overall anxiolytic effect, especially on the balancing modulation of the synaptic hippocampal transmission [111]. In conclusion, the above-argued hormones activate biomolecular pathways that have been connected to both synaptic plasticity and neuroprotection. Their beneficial effects are fundamental on memory, learning and dendritic spine structure and function

\section{Cell therapy: new perspectives}

Stem cell therapy is now incorporated in the contemporary field of medicine called 'regenerative medicine'. This is a new branch of medicine that deals with the 'process of regenerating human cells, tissues or organs to restore its established normal function.' It also includes stimulating the body's own repair mechanisms to heal dysfunctional tissues or organs [112]. Yet, cell therapy is an old medical technique, which involves implantation of human or animal cells into humans or animals in an attempt to repair cells damages and treat diseases. It is a state-of-the-art treatment in the area of regenerative medicine, demonstrated for the first time in 1912 by Nobel Prize winner Alexis Carrel in the rejuvenation of in vitro aged cells. In 1931, was applied in humans with great success by Dr. Paul Niehens [113]. The aim is to restore the functional capability of the cells, tissues and organs by the use of biological trophic factors, molecules and peptides, normally found and isolated from the cultured fetal, neonatal, juvenile or adult stage bio-identical cells. Cell therapy includes implantation using fresh cells, lyophilized [freeze-dried] cells, frozen cells and fetal precursor stem cell transplantation prepared by primary tissue culture [112] Interestingly, as far as concerning the cell type choice, some group studies appoint to the cells from fetuses or newborn rabbits reared in accredited closed colonies. The xenotransplantation technique may be a smart approach in alternative to human cells cause the mammals share all the same cytological level, except the frontal lobe, which is not found in others than humans (FCTI ). These animals are bred in adherence to the regulations of the American Association for Accreditation of Laboratory Animal Care [AAALAC] and the Food and Drug Administration [FDA], USA. These xenotransplants might have some advantages comparing to human stem cells, as it is impossible to have humans subjected to such stringent regulations. The aim is to use fetal precursor stem cell xenotransplants [FPSCXT] prepared by primary tissue culture for treatment of diseases [112]. Currently, stem cells prepared by the primary tissue culture technique have been shown to be even safer because the eleven days of culture allows detailed daily evaluation of the cultures for bacterial contamination and endotoxins. In case of any suspicion of contamination, the stem cell transplants will be immediately discarded [114]. Research has shown that the cells processed this way are even less immunogenic [114]. These are implanted without the use of any immunosuppression. [114]. Studies in cell biology have established the importance of the cell membrane as the "brain of the cell". Although the xenogeneic, heterologous or autologous cell implantation mechanisms are still unclear, the regenerative effects, most seen following live cell therapy, might be due to the cell signalling factors and molecules in the fetal precursors stem cells transplants acting on the corresponding cell membranes receptors ligands of the recipient and, thereby, regulating and reprogramming cell functions at epigenetic level [115]. For instance, it's becoming clearer that protein phosphorylation in nerve tissues is of a paramount importance and has several roles; included enzymes involved in neurotransmitter biosynthesis and neurotransmitter receptors [116]. The large amount of phosphorylated neuronal proteins and their membrane receptors, once transplanted, should activate a molecular and biochemical cascade on the recipient's site, boosting the neuronal repairing and neuroplasticity. The transplantation of human or animal stem/progenitor cells, for instance, can be an effective treatment for central nervous system [CNS] injury due to the self-renewing and pluripotential nature of these cells. Stem cells can repair injured nervous tissue by developing a regenerative appropriate environment of neuroprotection in which the damaged cells may be replaced by new functional ones. The stem cells can be distinguished by its origins, either from embryonic, fetal or adult and depending on that, the regenerative potential might be greater once transplanted into the impaired CNS [117]. The transplantation of bone marrow-derived mesenchymal stromal cells [MSCs] can be very promising because of the incredible potential of those cells in self-renewing, differentiating into multiple mesodermal tissues, including bone, cartilage, fat and muscle and been nonimmunogenic; which allows its prompt clinical using. As the mesenchymal stromal cells [MSCs] have the ability to produce cytokines and various neurotrophic factors [oligodendrocyte precursor cells, chemokine stromal cell-derived factor-1 [SCF1], brain natriuretic peptide [BNP], astrocytic BDNF, insulin growth factor-1 [IGF1], vascular endothelial growth factor [VEGF], fibroblast growth factor-2 [FGF2], transforming growth factor- $\beta$ [TGF- $\beta$ ], BDNF and nerve growth factor [NGF]]; can benefit every aspect of brain plasticity, including the modulation of angiogenesis, apoptosis, neurogenesis, synaptogenesis and dendritic proliferation $[117,118]$. Of course, there is a clear need to further research about the complicated network of cell therapy and stem cell biology, but, in summary, the promising innovation of the cell therapy is that exogenous cells factors, peptides and nutrients may provide therapeutic benefits to induce remodelling in the CNS, which raises improvement in neurological function.

\section{Discussion}

The applied neuroscience field is in a progressive and extensive development. Everyday, new molecules, biological pathways and cell mechanisms are being discovered and publishing. The challenge is to integrate the various previously discussed perspectives on brain neuroplasticity to fulfil the anti-aging neuronal extensive benefits. The orthomolecular concept stands on the wide vision that the modern physician or neuroscientist must have in connecting the interference of psychological stress with the disruption of the hypothalamichypophysis-adrenal axe, the enhancement of stress hormones such as cortisol, adrenaline and noradrenaline; the consequence of high oxidative stress molecules, immunosuppression, hormonal imbalances and inflammation. Together with the biological aging processes and the influence of genetics and epigenetics, there are also the social behaviour's outcomes, which depend on the curiosity of learning new tasks, exchange new experiences, meditate, practice daily exercises and have a proper diet. In a contemporary view of society, people are getting sicker and aging badly due to several important stressful and inflammatory triggers. Pollution with heavy metals, recurrent infections, excess of sugar and refined "junk food", sedentary life, excess of work, very few time to be curious, be social and learn novelties; lack of consciousness about relaxation and meditation... every path may lead to stress, chronic inflammation, immunosuppression, metabolic and hormonal imbalances and sickness. Either Mediterranean Diet or Okinawa Diet is very rich in anti-inflammatory dietary polyphenols, 
polyunsaturated fatty acids, proteins, fibres, probiotics, vitamins and further antioxidants. By mixing all these key functional nutrients with caloric restriction and moderate exercises, the epigenetic expression will be activating in order to regulate the transcription of neuroprotective proteins and growth factors, slowing aging typical degeneration. As far we discuss the new aspects of neurodegeneration treatments, we must give high importance to the hormonal and cell therapy, which offer very important possibilities on the neurotransmitters balance, tissue repairing, cell restoration and neuroplastic stimulation. Of course, more basic and experimental researches, meta-analysis and other clinical global assays are needed to dissect the still unclear mechanism of neuroplasticity and its related integrative medical treatments. The moment is timing is imperative for such interventions with goals of enhancing brain health throughout lifespan [119-127].

\section{Conclusion}

The functional brain has the ability to repair itself trough neuroplastic mechanisms that depends on anti-inflammatory/antioxidant type diet, caloric restriction, moderate exercises, new experiences, meditation, hormonal balance and regenerative cell neurotrophic factors. Having this orthomolecular point of view is imperative to develop the best strategies to enhance the long-living health quality.

\section{References}

1. International AD (2010) The World Alzheimer Report.

2. Amen DG (2012) Cognitive and Neurodegenerative Diseases and Impairments Cognitive Decline and Enhancement: Prevention Trough Dalay. In Encyclopedia of Clinical Anti-Aging Medicine and Regenerative Biomedical Technologies (pp. 219237) The American Academy of Anti-Aging Medicine.

3. Shankle WR (1998) Numbers of neurons per columm in the developing human cerebral cortex from birth to 72 months: Evidence for an apparent post-natal increase in neuron numbers. $J$ Theor Biol 191: 115-140.

4. Eriksson PS, Perfilieva E, Björk-Eriksson T, Alborn AM, Nordborg C, et al. (1998) Neurogenesis in the adult human hippocampus. Nat Med 4: 1313-1317. [Crossref]

5. Parasuraman PM (2010) Neuronal and cognitive plasticity: a neurocognitive framework for ameliorating cognitive aging. Frontiers in Aging Neuroscience 2: 150.

6. Butti E, Cusimano M, Bacigaluppi M, Martino G (2014) Neurogenic and nonneurogenic functions of endogenous neural stem cells. Front Neurosci 8: 1-11. [Crossref]

7. Mattson MP (2002) Neuroprotective and neurorestorative signal transduction mechanisms in brain aging: modi- fication by genes, diet and behavior. Neurobiol Aging 23: 695-705.

8. Anderson I, Adinolfi C, Doctrow S, Huffman K, Joy KA, et al. (2001) Oxidative signalling and inflammatory pathways in Alzheimer's disease. Biochem Soc Symp, pp: 141-149. [Crossref]

9. Chklovskii DB, Mel BW, Svoboda K (2004) Cortical rewiring and information storage. Nature 431: 782-788. [Crossref]

10. Dupont C, Armant DR, Brenner CA (2009) Epigenetics: Definition, Mechanisms and Clinical Perspective. Semin Reprod Med 27: 351-357. [Crossref]

11. Liu H, Song N (2016) Molecular Mechanism of Adult Neurogenesis and its Association with Human Brain Diseases. J Cent Nerv Syst Dis 8: 5-11. [Crossref]

12. Janson M (2006) Orthomolecular medicine: the therapeutic use of dietary supplements for anti-aging. Clin Interv Aging 1: 261-265. [Crossref]

13. Black PH, Garbutt LD (2002) Stress, inflammation and cardiovascular disease. $J$ Psychosom Res 52: 1-23. [Crossref]

14. Caterina Rosano AL (2012) Maintaining Brain Health by Monitoring Inflammatory Processes: a Mechanism to Promote Successful Aging. Aging and Disease 3: 16-33.

15. McNally L, Bhagwagar Z, Hannestad J (2008) Inflammation, glutamate, and glia in depression: a literature review. CNS Spectr 13: 501-510. [Crossref]
16. Perlmutter D (2012) Cognitive and Neurodegenerative Diseases and Impairments. The role of Inflammation in neurodegenerative Disorders. In: Encyclopedia of Clinical Anti-Aging Medicine and Regenerative Biomedical Technologies (pp. 185-191) American Academy of Anti-Aging Medicine.

17. Kiecolt-Glaser JK (2010) Stress, food, and inflammation: psychoneuroimmunology and nutrition at the cutting edge. Psychosom Med 72: 365-369. [Crossref]

18. Giugliano D, Ceriello A, Esposito K (2006) The effects of diet on inflammation emphasis on the metabolic syndrome. J Am Coll Cardiol 48: 677-685. [Crossref]

19. Esposito KNF (2003) Effect of dietary antioxidants on postprandial endothelial dysfunction induced by a high-fat meal in healthy subjects. Am J Clin Nutr 77: 139-143.

20. Raison CL, Capuron L, Miller AH (2006) Cytokines sing the blues: inflammation and the pathogenesis of depression. Trends Immunol 27: 24-31. [Crossref]

21. Vgontzas AN, Zoumakis E, Bixler EO, Lin HM, Follett H, et al. (2004) Adverse effects of modest sleep restriction on sleepiness, performance, and inflammatory cytokines. $J$ Clin Endocrinol Metab 89: 2119-2126. [Crossref]

22. Willcox DC, Scapagnini G, Willcox BJ (2014) Healthy aging diets other than the Mediterranean: a focus on the Okinawan diet. Mech Ageing Dev 136-137: 148-62. [Crossref]

23. Witte AV, Fobker M, Gellner R, Knecht S, Flöel A (2009) Caloric restriction improves memory in elderly humans. Proc Natl Acad Sci U S A 106: 1255-1260. [Crossref]

24. Fusco S, Pani G (2013) Brain response to calorie restriction. Cell Mol Life Sci 70: 3157-3170. [Crossref]

25. Rothman SM, Mattson MP (2012) Activity-dependent, stress-responsive BDNF signaling and the quest for optimal brain health. Neuroscience 239: 228-240. [Crossref]

26. Pasinetti GM, Zhao Z, Qin W, Ho L, Shrishailam Y, et al. (2007) Caloric intake and Alzheimer's disease. Experimental approaches and therapeutic implications. Interdiscip Top Gerontol 35: 159-175. [Crossref]

27. Knight A, Bryan J, Murphy K (2016) Is the mediterranean diet a feasible approach to preserving cognitive function and reducing risk of dementia for older adults in western countries? new insights and future directions. Ageing Res Rev 25: 85-101. [Crossref]

28. Shaffer J (2016) Neuroplasticity and Clinical Practice: Building Brain Power for Health. Front Psychol 7: 1118. [Crossref]

29. Gomez-Pinilla F, Tyagi E (2013) Diet and cognition: interplay between cell metabolism and neuronal plasticity. Curr Opin Clin Nutr Metab Care 16: 726-733. [Crossref]

30. Zuccato C, Cattaneo E (2009) Brain-derived neurotrophic factor in neurodegenerative diseases. Nat Rev Neurol 5: 311-322. [Crossref]

31. Gomez-Pinilla F, Gomez AG (2011) The influence of dietary factors in central nervous system plasticity and injury recovery. $P M R 3: \mathrm{S} 111-116$. [Crossref]

32. Barberger-Gateau P (2014) Nutrition and brain aging: how can we move ahead? Eur J Clin Nutr 68: 1245-1249. [Crossref]

33. Maes M, Christophe A, Bosmans E, Lin A, Neels H (2000) In humans, serum polyunsaturated fatty acid levels predict the response of proinflammatory cytokines to psychologic stress. Biol Psychiatry 47: 910-920. [Crossref]

34. Jones CR, Arai T, Rapoport SI (1997) Evidence for the involvement of docosahexaenoic acid in cholinergic stimulated signal transduction at the synapse. Neurochem Res 22: 663-670. [Crossref]

35. Wu A, Ying Z, Gomez-Pinilla F (2007) Omega-3 fatty acids supplementation restores mechanisms that maintain brain homeostasis in traumatic brain injury. $J$ Neurotraum 24: 1587-1595. [Crossref]

36. Schaefer EJ, Bongard V, Beiser AS, Lamon-Fava S, Robins SJ (2006) Plasma phosphatidylcholine docosahexaenoic acid content and risk of Dementia and Alzheimer disease: the framingham heart study. Arch Neurol 63: 1545-1550. [Crossref]

37. Boespflug EL, McNamara RK, Eliassen JC, Schidler MD, Krikorian R (2016) Fish oi supplementation increases event-related posterior cingulate activation in older adults with subjective memory impairment. J Nutr Health Aging 20: 161-169. [Crossref]

38. Spencer JP (2009) Flavonoids and brain health: multiple effects underpinned by common mechanisms. Genes Nutr 4: 243-250. [Crossref]

39. Dauncey MJ (2014) Nutrition, the brain and cognitive decline: insights from epigenetics. Eur J Clin Nutr 68: 1179-1185. [Crossref]

40. Sun AY, Wang Q, Simonyi A, Sun GY (2010) Resveratrol as a therapeutic agent for neurodegenerative diseases. Mol Neurobiol 41: 375-383. [Crossref] 
41. Kim SJ, Son TG, Park HR, Park M, Kim MS, et al. (2008) Curcumin stimulates proliferation of embryonic neural progenitor cells and neurogenesis in the adult Hippocampus. J Biol Chem 283: 14497-14505. [Crossref]

42. Cox KH, Pipingas A, Scholey AB (2015) Investigation of the effects of solid lipid curcumin on cognition and mood in a healthy older population. J Psychopharmacol 29 : 642-651. [Crossref]

43. Nehlig A (2013) The neuroprotective effects of cocoa flavanol and its influence on cognitive performance. Br J Clin Pharmacol 75: 716-727. [Crossref]

44. Latif R (2013) Health benefits of cocoa. Curr Opin Clin Nutr Metab Care 16: 669-674. [Crossref]

45. Brickman AM, Khan UA, Provenzano FA, Yeung LK, Suzuki W, et al. (2014) Enhancing dentate gyrus function with dietary flavanols improves cognition in older adults. Neurosci 17: 1798-1803. [Crossref]

46. Unno K, Takabayashi F, Yoshida H, Choba D, Fukutomi R, et al. (2007) Daily consumption of green tea catechin delays memory regression in aged mice. Biogerontology 8: 89-95. [Crossref]

47. Fioravanti M, Ferrario E, Massaia M, Cappa G, Rivolta G, et al. (1997) Low folate levels in the cognitive decline of elderly patients and efficacy of folate as a treatment for improving memory deficits. Arch Gerontol Geriatr 26: 1-13. [Crossref]

48. Durga J, van Boxtel MP, Schouten EG, Kok FJ, Jolles J, et al. (2007) Effect of 3-year folic acid supplementation on cognitive function in older adults in the FACIT trial: a randomised, double blind, controlled trial. Lancet 369: 208-216. [Crossref]

49. Liu J (2008) The effects and mechanisms of mitochondrial nutrient a-lipoic acid on improving age-associated mitochondrial and cognitive dysfunction: an overview. Neurochem Res 33(1): 194-203. [Crossref]

50. Holmquist L, Stuchbury G, Berbaum K, Muscat S, Young S, et al. (2007) Lipoic acid as a novel treatment for Alzheimer's disease and related dementias. Pharmacol Ther 113: 154-164. [Crossref]

51. Wu A, Ying Z, Gomez-Pinilla F (2004) The interplay between oxidative stress and brain-derived neurotrophic factor modulates the outcome of a saturated fat diet on synaptic plasticity and cognition. Eur J Neurosci 19(7): 1699-1707. [Crossref]

52. Shults CW, Beal MF, Fontaine D, Nakano K, Haas RH (1998) Absorption, tolerability, and effects on mitochondrial activity of oral coenzyme Q10 in parkisonian patients. Neurology 50: 793-795. [Crossref]

53. Eyles D, Burne T, McGrath J (2011) Vitamin D in fetal brain development. Semin Cell Dev Biol 22: 629-636. [Crossref]

54. McCann JC, Hudes M, Ames BN (2006) An overview of evidence for a causa relationship between dietary availability of choline during development and cognitive function in offspring. Neurosci Biobehav Rev 30: 696-712. [Crossref]

55. Schram MT, Trompet S, Kamper AM, de Craen AJ, Hofman A, et al. (2007) Serum calcium and cognitive function in old age. J Am Geriatr Soc 55: 1786-1792. [Crossref]

56. Gao S, Jin Y, Hall KS, Liang C, Unverzagt FW, et al. (2007) Selenium level and cognitive function in rural elderly Chinese. Am J Epidemiol 165: 955-965. [Crossref]

57. Ortega RM, Requejo AM, Andrés P, López-Sobaler AM, Quintas ME, et al. (1997) Dietary intake and cognitive function in a group of elderly people. Am J Clin Nutr 66 : 803-809. [Crossref]

58. Blaylock RL (2012) Cognitive and Neurodegenerative Diseases \& Impairments: Approach to Concussion and Associated Neurodegeneration. In: Encyclopedia of Clinical Anti-Aging Medicine \& Regenerative Biomedical Technologies (pp. 239-261) Chiacago, USA: American Academy of Anti-Aging Medicine.

59. Molteni R, Wu A, Vaynman S, Ying Z, Barnard RJ, et al. (2004) Exercise reverses the harmful effects of consumption of a high-fat diet on synaptic and behavioral plasticity associated to the action of brain-derived neurotrophic factor. Neuroscience 123: 429440. [Crossref]

60. Niemann C, Godde B, Voelcker-Rehage C (2014) Not only cardiovascular, but also coordinative exercise increases hippocampal volume in older adults. Front Aging Neurosci 6: 170. [Crossref]

61. Tian Q, Erickson KI, Simonsick EM, Aizenstein HJ, Glynn NW, et al. (2014) Physical activity predicts microstructural integrity in memory-related networks in very old adults. J Gerontol A Biol Sci Med Sci 69(10): 1284-1290. [Crossref]

62. Pereira AC, Huddleston DE, Brickman AM, Sosunov AA, Hen R, et al. (2007) An in vivo correlate of exercise-induced neurogenesis in the adult dentate gyrus. Proc Natl Acad Sci U S A 104: 5638-5643. [Crossref]
63. Snyder JS, Glover LR, Sanzone KM, Kamhi JF, Cameron HA (2009) The effects of exercise and stress on the survival and maturation of adult-generated granule cells. Hippocampus 19: 898-906. [Crossref]

64. Erickson KI, Leckie RL, Weinstein AM (2014) Physical activity, fitness, and gray matter volume. Neurobiol Aging 35 Suppl 2: S20-28. [Crossref]

65. Hillman CH, Erickson KI, Kramer AF (2008) Be smart, exercise your heart: exercise effects on brain and cognition. Nat Rev Neurosci 9(1): 58-65. [Crossref]

66. Vaynman S, Gomez-Pinilla F (2005) License to run: exercise impacts functional plasticity in the intact and injured central nervous system by using neurotrophins. Neurorehabil Neural Repair 19: 283-295. [Crossref]

67. Mahncke HW, Bronstone A, Merzenich MM (2006) Brain plasticity and functional losses in the aged: scientific bases for a novel intervention. Prog Brain Res 157: 81109. [Crossref]

68. Vemuri P, Lesnick TG, Przybelski SA, Machulda M, Knopman DS, et al. (2014) Association of lifetime intellectual enrichment with cognitive decline in the older population. JAMA Neurol 71: 1017-1024. [Crossref]

69. Paraskevopoulos E, Kuchenbuch A, Herholz SC, Pantev C (2012) Musical expertise induces audiovisual integration of abstract congruency rules. J Neurosci 32: 1819618203. [Crossref]

70. Kuchenbuch A, Paraskevopoulos E, Herholz SC, Pantev C (2014) Audio-tactile integration and the influence of musical training. PLoS One 9: e85743. [Crossref]

71. Seinfeld S, Figueroa H, Ortiz-Gil J, Sanchez-Vives MV (2013) Effects of music learning and piano practice on cognitive function, mood and quality of life in older adults. Front Psychol 4: 810. [Crossref]

72. Benz S, Sellaro R, Hommel B, Colzato LS (2016) Music Makes the World Go Round: The Impact of Musical Training on Non-musical Cognitive Functions-A Review. Front Psychol 6: 2023. [Crossref]

73. Ball K, Berch DB, Helmers KF, Jobe JB, Leveck MD, et al. (2002) Effects of cognitive training interventions with older adults: a randomized controlled trial. JAMA 288 2271-2281. [Crossref]

74. Ball KK, Ross LA, Roth DL, Edwards JD (2013) Speed of processing training in the ACTIVE study: how much is needed and who benefits? J Aging Health 25: 65S-84S. [Crossref]

75. Luders E, Cherbuin N, Kurth F (2015) Forever Young(er): potential age-defying effects of long-term meditation on gray matter atrophy. Front Psychol 5: 1551. [Crossref]

76. Tang YY, Lu Q, Fan M, Yang Y, Posner MI (2012) Mechanisms of white matter changes induced by meditation. Proc Natl Acad Sci US A 109: 10570-10574. [Crossref]

77. Kaliman P, Alvarez-López MJ, Cosín-Tomás M, Rosenkranz MA, Lutz A, et al. (2014) Rapid changes in histone deacetylases and inflammatory gene expression in expert meditators. Psychoneuroendocrinology 40: 96-107. [Crossref]

78. Plant DT, Trksak GH, Jensen JE, Penetar DM, Ravichandran C, et al. (2014) Gray matter-specific changes in brain bioenergetics after acute sleep deprivation: a $31 \mathrm{P}$ magnetic resonance spectroscopy study at 4 Tesla. Sleep 37: 1919-1927.

79. Joo EY, Kim H, Suh S, Hong SB (2014) Hippocampal substructural vulnerability to sleep disturbance and cognitive impairment in patients with chronic primary insomnia: magnetic resonance imaging morphometry. Sleep 37(7): 1189-1198. [Crossref]

80. Zielinski MR, Kim Y, Karpova SA, McCarley RW, Strecker RE, et al. (2014) Chronic sleep restriction elevates brain Interleukin-1 beta and tumor necrosis factor-alpha and attenuates brain-derived neurotrophic factor expression. Neurosci Lett 580: 27-31. [Crossref]

81. Jessen NA, Munk AS, Lundgaard I, Nedergaard M (2015) The Glymphatic System: A Beginner's Guide. Neurochem Res 40: 2583-2599. [Crossref]

82. Iguichi H, Kato K, Ibayashi H (1982) Age-dependent reduction in serum melatonin concentrations in healthy human subjects. J Clin Endocrinol Metab 55: 27-29. [Crossref]

83. Hardeland R, Cardinali D, Srinivasan V, Spence D, Brown G, et al. (2011) Melatonin-A pleiotropic, orchestrating regulator molecule. Prog Neurobiol 93: 350-384. [Crossref]

84. Reiter RJ, Manchester LC, Tan DX (2010) Neurotoxins: free radical mechanisms and melatonin protection. Curr Neuropharmacol 8: 194-210. [Crossref]

85. Tan DX, Manchester LC, Esteban-Zubero E, Zhou Z, Reiter RJ (2015) Melatonin as a Potent and Inducible Endogenous Antioxidant: Synthesis and Metabolism. Molecules 20: 18886-18906. [Crossref] 
86. Pandi-Perumal S, BaHammam A, Brown G, Spence D, Bharti V, et al. (2013) Melatonin antioxidative defense: therapeutical implications for aging and neurodegenerative processes. Neurotox Res 23: 267-300. [Crossref]

87. Lin L, Huang QX, Yang SS, Chu J, Wang JZ, et al. (2013) Melatonin in Alzheimer's disease. Int J Mol Sci 14: 14575-14593. [Crossref]

88. Zhang X, Liu L, Jiang S, Zhong Y, Yang X (2011) Activation of the zeta receptor 1 suppresses NMDA responses in rat retinal ganglion cells. Neuroscience 177: 12-22.

89. Ramírez-Rodríguez G, Vega-Rivera N, Benítez-King G, Castro-García M, OrtízLópez L (2012) Melatonin supplementation delays the decline of adult hippocampal neurogenesis during normal aging of mice. Neurosci Lett 530: 53-58. [Crossref]

90. Bulieu EE, Robel P (1998) Dehydroepiandrosterone (DHEA) and dehydroepiandrosterone sulfate (DHEAS) as neuroactive neurosteroids. Proc Natl Acad Sci U S A 95: 4089-4091. [Crossref]

91. Sunderland T, Merril CR, Harrington MG, Lawlor BA, Molchan SE, et al. (1989) Reduced plasma dehydroepiandrosterone concentrations in Alzheimer's disease. Lancet 2: 570. [Crossref]

92. Moriguchi S, Yamamoto Y, Ikuno T, Fukunaga K (2011) Sigma-1 receptor stimulation by dehydroepiandrosterone ameliorates cognitive impairment through activation of CaM kinase II, protein kinase $\mathrm{C}$ and extracellular signal-regulated kinase in olfactory bulbectomized mice. J Neurochem 117: 879-891.

93. Moriguchi S, Shinoda Y, Yamamoto Y, Sasaki Y, Miyajima K, et al. (2013) Stimulation of the sigma-1 receptor by DHEA enhances synaptic efficacy and neurogenesis in the hippocampal dentate gyrus of olfactory bulbectomized mice. PLOS ONE 8: e60863.

94. Ishima T, Nishimura T, Iyo M, Hashimoto K (2008) Potentiation of nerve growth factor-induced neurite outgrowth in PC12 cells by donepezil: Role of sigma-1 receptors and IP3 receptors. Prog Neuropsychopharmacol Biol Psychiatry 32: 1656-1659.

95. Paz-Filho GJ (2016) The Effects of Leptin Replacement on Neural Plasticity. Neural Plast 2016: 8528934. [Crossref]

96. Bouret SG (2010) Neurodevelopmental actions of leptin. Brain Res 1350: 2-9. [Crossref]

97. Morrison CD (2009) Leptin signaling in brain: A link between nutrition and cognition? Biochim Biophys Acta 1792: 401-408. [Crossref]

98. Baudry M, Bi X, Aguirre C (2013) Progesterone-estrogen interactions in synaptic plasticity and neuroprotection. Neuroscience 239: 280-294. [Crossref]

99. Beyer C, Green SJ, Hutchison JB (1994) Androgens influence sexual differentiation of embryonic mouse hypothalamic aromatase neurons in vitro. Endocrinology 135: 12201226. [Crossref]

100. Lue YH, H. A. (1999) Single exposure to heat in- duces stage-specific germ cell apoptosis in rats: role of intratesticular testosterone in stage specificity. Endocrinology 141: $1709-1717$.

101. Białek M, Zaremba P, Borowicz KK, Czuczwar SJ (2004) Neuroprotective role of testosterone in the nervous system. Pol J Pharmacol 56: 509-518. [Crossref]

102. Cherrier MM, Asthana S, Plymate S, Baker L, Matsumoto AM (2001) Testosterone supplementation improves spatial and verbal memory in healthy older men. Neurology 57: 80-88. [Crossref]

103. Lim D, Flicker L, Dharamarajan A, Martins RN (2003) Can testosterone replacement decrease the memory problem of old age? Med Hypotheses 60: 893-896. [Crossref]

104. Tirassa P, Thiblin I, Agren G, Vigneti E, Aloe L, et al. (1997) High-dose anabolic steroids modulate concen- tration of nerve-growth factor and expression of its low affinity receptor (p75-ngFr) in male rat brain. J Neurosci Res 47: 198-207. [Crossref]

105. Bueno J, Pfaff DW (1976) Single unit recording in hypothalamus and preoptic area of estrogen-treated and untreated ovariectomized female rats. Brain Res 101: 67-78. [Crossref]

106. Toran-Allerand CD (1976) Sex steroids and the development of the newborn mouse hypothalamus and preoptic area in vitro: implications for sexual differentiation. Brain Res 106: 407-412.
107. Lösel R, Wehling M (2003) Nongenomic actions of steroid hormones. Nat Rev Mol Cell Biol 4: 46-56. [Crossref]

108. Srivastava DP, Woolfrey KM, Penzes P (2013) Insights into rapid modulation of neuroplasticity by brain estrogens. Pharmacol Rev 65: 1318-1350. [Crossref]

109. Frankfurt M, Luine V (2015) The evolving role of dendritic spines and memory: Interaction(s) with estradiol. Horm Behav 74: 28-36. [Crossref]

110. Gonzalez SL, Labombarda F, Gonzalez Deniselle MC, Mougel A, Guennoun R, et al. (2005) Progesterone neuroprotection in spinal cord trauma involves up-regulation of brain-derived neurotrophic factor in motoneurons. J Steroid Biochem Mol Biol 94 143-149. [Crossref]

111. Foy MR, Akopian G, Thompson RF (2008) Progesterone regulation of synaptic transmission and plasticity in rodent hippocampus. Learn Mem 15: 820-822. [Crossref]

112. Jalil DA (2016) Hope for untreatable medical disorders with live cell therapy Typeset in by Troubador Publishing Ltd, Leicester, UK.

113. Niehans P (1960) Introduction to Cell Therapy. New York: Peageant Books Inc

114. Molnar EM (2006) Textbook of Stem Cell Transplantation. Medical and Engineering Publishers.

115. Schmid F (1983) Cell Therapy: A Dimension of Medicine. Switzland: Ott Publishing

116. Culbert RW (1996) The Biochemical Basis of Live Cell Therapy. The Bradford Institute.

117. Parr AM, Tator CH, Keating A (2007) Bone marrow-derived mesenchymal stroma cells for the repair of central nervous system injury. Bone Marrow Transplant 40: 609-619. [Crossref]

118. Pittenger MF, Mackay AM, Beck SC, Jaiswal RK, Douglas R, et al. (1999) Multilineage potential of adult human mesenchymal stem cells. Science 284: 143147. [Crossref]

119. Li Y, Chopp M (2009) Marrow stromal cell transplantation in stroke and traumatic brain injury. Neurosci Lett 456: 120-123. [Crossref]

120. Herrera-Arozamena C, Martí-Marí O, Estrada M, de la Fuente Revenga M, RodríguezFranco MI (2016) Recent Advances in Neurogenic Small Molecules as Innovative Treatments for Neurodegenerative Diseases. Molecules 21: 1165. [Crossref]

121. Garza JC, Guo M, Zhang W, Lu XY (2012) Leptin restores adult hippocampa neurogenesis in a chronic unpredictable stress model of depression and reverses glucocorticoid-induced inhibition of GSK-3ß/ß-catenin signaling. Molecular Psychiatry 17: 790-808. [Crossref]

122. Wengreen HJ, Munger RG, Corcoran CD, Zandi P, Hayden KM, et al. (2007) Antioxidant intake and cognitive function of elderly men and women: The Cache County Study. J Nutr Health Aging 11: 230-237. [Crossref]

123. Black PH, Garbutt LD (2002) Stress, inflammation and cardiovascular disease. $J$ Psychosom Res 52: 1-23. [Crossref]

124. Maes M, Christophe A, Bosmans E, Lin A, Neels H (2000) In humans, serum polyunsaturated fatty acid levels predict the response of proinflammatory cytokines to psychologic stress. Biol Psychiatry 47: 910-920. [Crossref]

125. O’Malley D, MacDonald N, Mizielinska S, Connolly CN, Irving AJ (2007) Leptin promotes rapid dynamic changes in hippocampal dendritic morphology. Molecular and Cellular Neuroscience 35: 559-572. [Crossref]

126. Przybelski RJ, Binkley NC (2007) Is vitamin D important for preserving cognition? A positive correlation of serum 25 -hydroxyvitamin D concentration with cognitive function. Arch Biochem Biophys 460: 202-205. [Crossref]

127. Udagawa J, Nimura M, Otani H (2006) Leptin affects oligodendroglial development in the mouse embryonic cerebral cortex. Neuro Endocrinol Lett 27: 177-182. [Crossref]

Copyright: (C2017 Moya RL. This is an open-access article distributed under the terms of the Creative Commons Attribution License, which permits unrestricted use, distribution, and reproduction in any medium, provided the original author and source are credited. 